\title{
Ceramic Materials: An Alternative for Surgical Saws
}

\author{
ljaz UI M*, David S and Ruediger H
}

Institute of Materials and Processes, University of Applied Sciences, Moltkestrasse 3076133, Karlsruhe, Germany

\begin{abstract}
The surgical saws were developed from $3 \% \mathrm{Y}$-TZP and $12 \% \mathrm{Ce}-\mathrm{ZrO}$ powders. The specimens were isostatic pressed and sintered conventionally. The saw-teeth were machined by CNC machine using diamond tool. The investigation includes the raise in temperature in bone tissue during cutting process with respect to increase in cutting speed and pressure. Thermal damage of bone tissue would be harmful in case of recovery. The rise in temperature during cutting of bone by ceramic saw was compared with stainless steel saw. The significantly lower temperature during bone cutting, excellent corrosion resistance after sterilization, hardness, wear and abrasive resistance properties show the advantages of 3Y-TZP ceramic saws in orthopedic surgeries.
\end{abstract}

Keywords: Ceramic powder; Sintering; Machining; Thermal effect; Mechanical properties

\section{Introduction}

The biocompatibility is the most important issue for the application of medical ceramics whether biopassive, bioactive, or resorbable ceramics. Medical ceramic materials often include glasses, glass ceramics, and ceramic-polymer bioactive composites.

The fabrication of tough and strong ceramics, long a goal of ceramic scientists, is difficult to achieve because of their inherent brittleness. Tetragonal zirconia (TZP) or zirconia-based ceramics have attracted special attention because of their excellent mechanical properties and attractive possibility of obtaining a nano-grained bulk ceramic with a controllable microstructure and improved properties.

Zirconia based ceramic materials have obtained extensive interest in the past decades due to their advanced mechanical and electrical properties. The high fracture toughness and strength of $3 \mathrm{~mol} \%$ yttria stabilized tetragonal zirconia polycrystals (3Y-TZP) make this material an important candidate for many structural applications $[1,2]$. Ceria stabilized tetragonal zirconia polycrystalline ceramics possess distinct advantages over other conventional structural ceramic materials because of their better thermal stability in moist environments [3]. The highly improved mechanical properties in these transformation toughened ceramics are related to the stress induced transformation of the metastable tetragonal grains to the monoclinic phase at the crack tips [4].

Ceramic materials have less wear and lower friction than stainless steel materials and can be advantageous over steel based materials. The friction coefficient of ceramics is lower than for steels by a factor of 3 to 10 [5]. A ceramic saw, due to the better friction properties, results in less heat generation and thus results in less temperature increase during bone cutting as compared to stainless steel material.

The temperature of the bone will rise more during the cutting process due to its poor thermal heat transport and smaller percentage of heat carried away by the chips, as compared to other engineering materials of higher thermal conductivity and heat capacity such as metals [6]. The heat generated during bone cutting is due to its lower value of thermal conductivity compared to that of metals.

The knowledge of thermal properties such as thermal conductivity, specific heat and coefficient of thermal expansion are essential in any work devoted to the goal of understanding and reducing thermal necrosis during cutting procedures in which heat is produced.
The elevated temperatures, which result from such exposure, may lead to cell death, i.e., to thermal necrosis, which in turn can lead to infection and reduced mechanical strength [7]. One of the most thorough investigations on threshold temperature was done by Moritz and Henriques [8]. They measured the amount of time required to produce damage to the dermal and epidermal layers of both human and porcine skin over a large temperature range $\left(44^{\circ} \mathrm{C}\right.$ to $\left.100^{\circ} \mathrm{C}\right)$. They established, for instance, that a temperature of $70^{\circ} \mathrm{C}$ will kill the epithelial cells immediately, and a temperature of $50^{\circ} \mathrm{C}$ will do so after 30 seconds. Similarly, a temperature of $45^{\circ} \mathrm{C}$ would have to be maintained for more than five hours to harm the cells.

In the present work, a ceramic saw blades with yttria and ceria stabilized zirconia powders were developed. The ceramic powder materials were pressed by cold isostatic compression and subsequently sintered at $1450-1500^{\circ} \mathrm{C}$. The sintered products were ground to the desired thickness and the teeth were also grinded by diamond disc. The temperature rise during bone cutting was measured. The mechanical properties of ceramic saw have also shown appropriate results for the orthopedic surgeries.

\section{Experimental Procedure}

The 3\% Yttria and $12 \%$ Ce stabilized $\mathrm{ZrO}_{2}$ powders were used for surgical saws.

Ceramic powder samples were isostatic pressed with a pressure of 3000 bar. The parts were milled in green state to the outer dimension except for the height of the blades. The compressed specimens were thermally de-binded at $500^{\circ} \mathrm{C}$ under air to remove the acrylic based binder and subsequently sintered at $1450-1500^{\circ} \mathrm{C}$ with a holding time of 2 hours. After sintering the parts were ground with a diamond coated grinding wheel to the actual height/thickness.

The teeth geometry was machined in a CNC-machine (Hawemat

*Corresponding author: ljaz UI M, Institute of Materials and Processes, University of Applied Sciences, Moltkestrasse 3076133, Karlsruhe, Germany, Tel: $+49(0) 721$ 925-1908; E-mail: ijaz-ul.mohsin@hs-karlsruhe.de

Received September 13, 2016; Accepted September 21, 2016; Published September 27, 2016

Citation: ljaz UM, David S, Ruediger H (2016) Ceramic Materials: An Alternative for Surgical Saws. Bioceram Dev Appl 6: 097. doi: 10.4172/2090-5025.1000097

Copyright: @ 2016 ljaz UM, et al. This is an open-access article distributed under the terms of the Creative Commons Attribution License, which permits unrestricted use, distribution, and reproduction in any medium, provided the original author and source are credited. 
$2001 \mathrm{CNC} / \mathrm{ECO}$ ) with special tools for ceramic (Diamond Grinding Wheel Q-Flute; grain: D54) (Figure 1). Required mechanical properties, microstructure analysis and temperature rise during bone cutting were measured. The simulated results were also compared with experimental results.

\section{Results and Discussion}

The ceramic powder materials were isostatic pressed at 3000 bar. The detail characteristics of the selected material are listed in Table 1.

The sintered machined saw blade was examined by optical microscope for micro cracks and sharpness of saw teeth (see encircled area in Figure 2); the study revealed that sharpness is slightly less than for stainless steel saw blades. The reason could be the brittleness of ceramic material. Grinding and machining of sintered ceramics is a very critical task. This can be minimized to some extend by optimizing teeth machining.

\section{Numerical modelling to calculate cutting temperature}

The measurement of thermal properties of bone is important to calculate the temperature rise in bone in a cutting process using analytical and numerical modelling. Despite the fact that all orthopedic interventions induce significant thermal effects, the thermal properties of bone are less well documented than mechanical ones. The heat capacity and thermal conductivity of bone are important factors affecting a temperature rise during the cutting operation. These factors have an inverse relationship with the temperature rise. The lower the values, the higher the temperatures generated in the material being cut.

Cutting-bone simulation is quite complicated to calculate the predicted temperature. The bone geometry was designed by Creo 2.0 software and standard physical properties of bone was assigned to the geometry as a material. To simplify the scenario, calculated thermal load was defined at bone according to cut area. Thermal load was calculated by applied force (during cut) and speed/velocity of the saw blade and friction coefficient of the ceramic material (Figure 3). This simulation optimized with respect to design of experiments (DOE) by using Creo 2.0 software and steady state thermal analysis was carried out. In similar way, the stainless steel saw blade cutting simulation was conducted. The simulated cutting temperature (stainless steel-maxtemperature $178^{\circ} \mathrm{C}$ and ceramic- max-temperature $104^{\circ} \mathrm{C}$ ) is slightly high than experimental (stainless steel-max-temperature $124^{\circ} \mathrm{C}$ and ceramic- max-temperature $94^{\circ} \mathrm{C}$ ). The reason could be that room cooling effect from atmosphere (room temperature $10^{\circ} \mathrm{C}$ ) and also could be the other bone materials (horse bone).
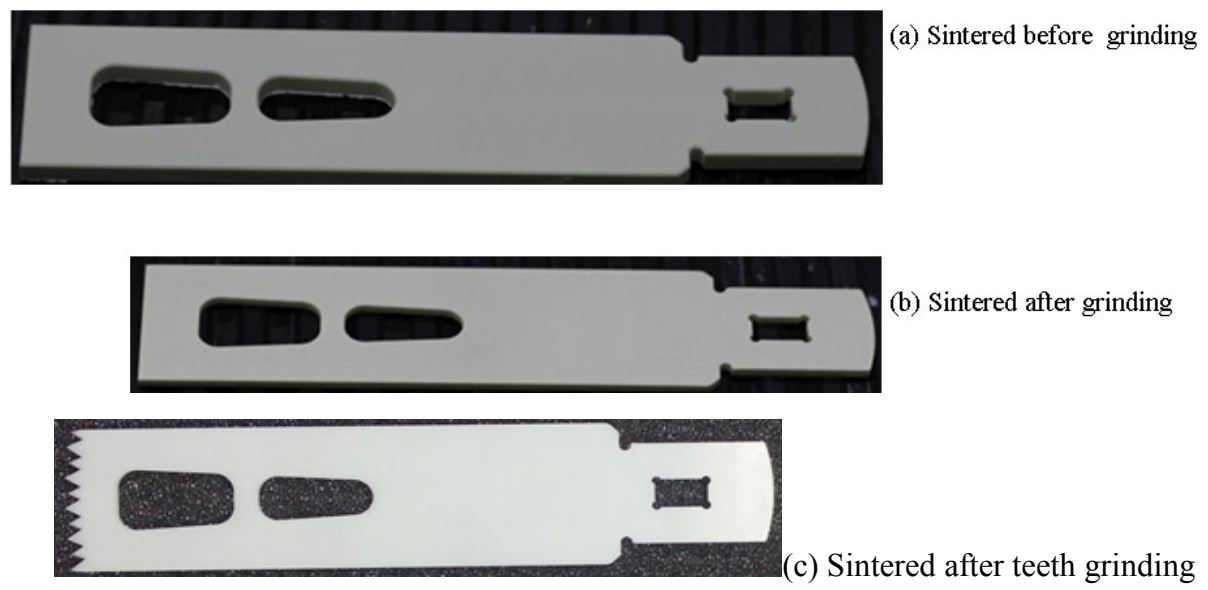

Figure 1: Systematic diagram of manufacturing a ceramic saw blade.

\begin{tabular}{|c|c|c|c|c|c|c|c|c|c|}
\hline \multirow[t]{2}{*}{ Material } & \multicolumn{3}{|c|}{ Particle Size $(\mu \mathrm{m})$} & \multirow{2}{*}{$\begin{array}{l}\text { Sintering temperature } \\
\left({ }^{\circ} \mathrm{C}\right)\end{array}$} & \multirow{2}{*}{$\begin{array}{c}\text { Sintered density } \\
\left(\mathrm{g} / \mathrm{cm}^{3}\right)\end{array}$} & \multirow{2}{*}{$\begin{array}{l}\text { Char. biaxial } \\
\text { strength(Mpa) }\end{array}$} & \multirow{2}{*}{$\begin{array}{l}\text { Weibull } \\
\text { modulus }\end{array}$} & \multirow{2}{*}{$\begin{array}{l}\text { Fracture toughness } \\
\qquad\left(\mathrm{MPa}^{*} \mathrm{~m} 0.5\right)\end{array}$} & \multirow{2}{*}{$\begin{array}{l}\text { Hardness } \\
\text { (HV1) }\end{array}$} \\
\hline & $\left(D_{10}\right)$ & $\left(D_{50}\right)$ & $\left(D_{90)}\right.$ & & & & & & \\
\hline $3 \mathrm{Y}-\mathrm{ZrO}_{2}$ & 0.32 & 7.59 & 24.08 & 1480 & 6.066 & 1510 & 18.3 & 8 & 1420 \\
\hline $12 \mathrm{Ce}-\mathrm{ZrO}_{2}$ & 0.22 & 0.92 & 16.24 & 1500 & 5.6 & 1545 & 10 & & 1120 \\
\hline
\end{tabular}

Table 1: Characteristics of selected material.
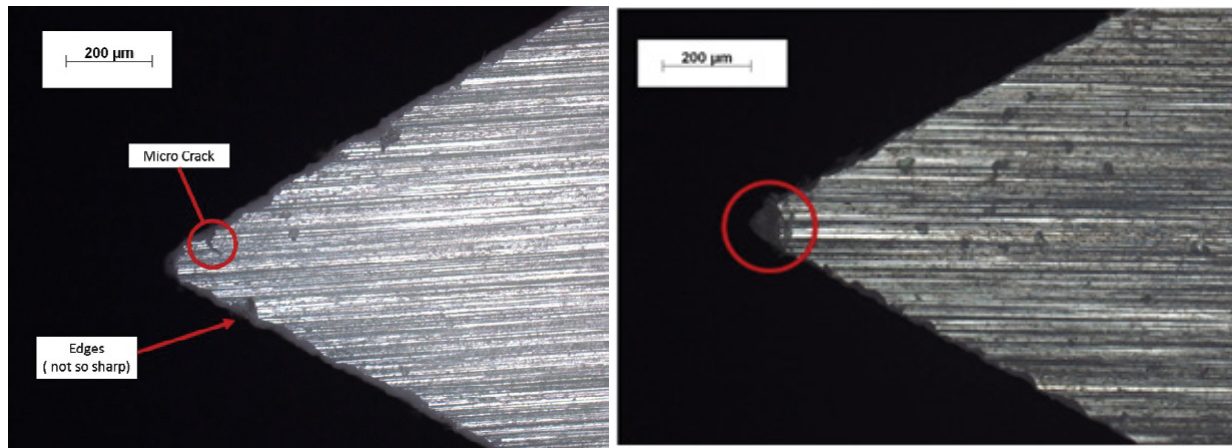

Figure 2: Micro-cracks and sharpness analysis of $12 \mathrm{Ce}-\mathrm{ZrO}_{2}$ (left) and $3 \mathrm{Y}-\mathrm{ZrO}_{2}$ (right) saw blades. 


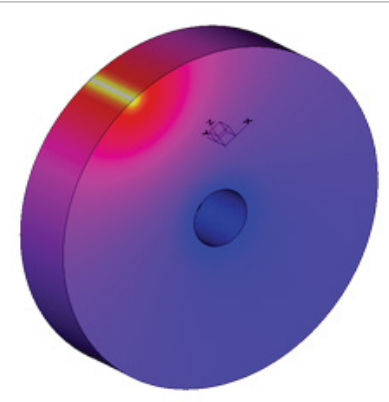

(a) Stainless steel saw blade.

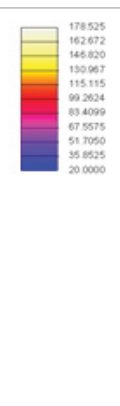

(b) Ceramic saw blade

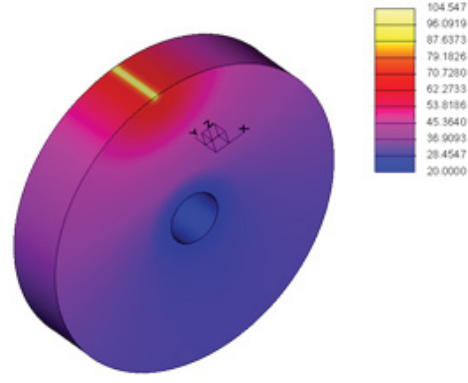

Figure 3: Creo 2.0-Thermal simulation of bone cut: (a) stainless steel, (b) $3 \mathrm{Y}^{-} \mathrm{ZrO}_{2}$ ceramic.

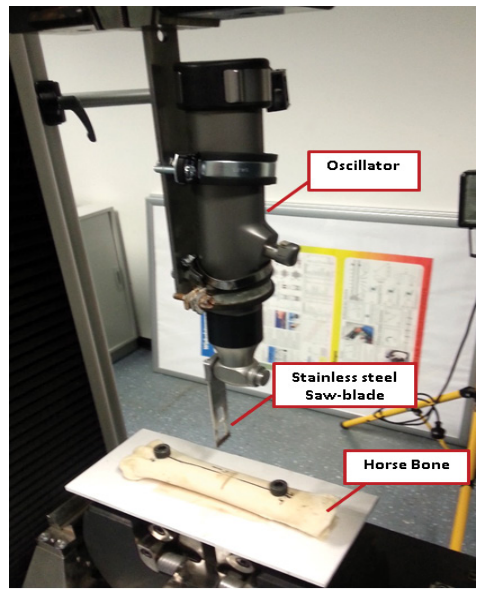

Figure 4: Test stand for measuring the cutting temperature.
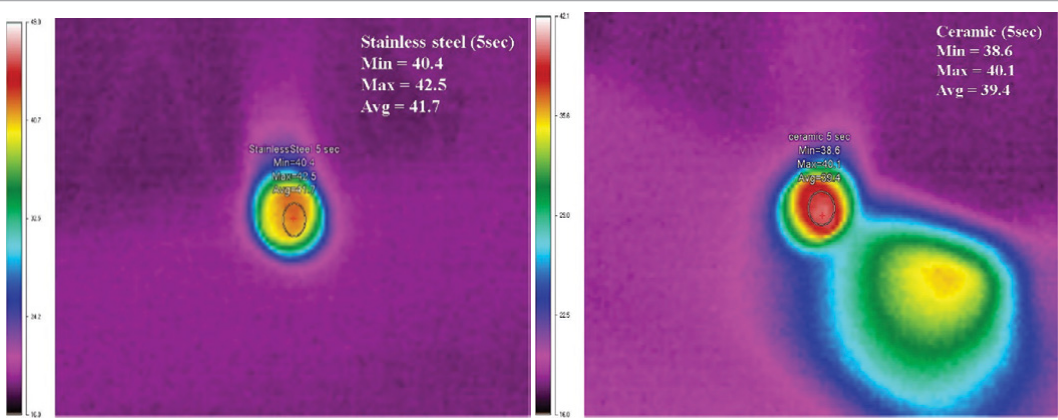

Figure 5: Fluke Ti20 thermal camera at bone cut by stainless steel saw and $3 \mathrm{Y}_{-} \mathrm{ZrO}{ }_{2}$ ceramic (after $5 \mathrm{sec}$ ).

\section{Experimental temperature measurements in horse-bone cutting}

The test stand was prepared in such a manner that the applied force can be controlled during bone cutting and battery oscillator are kept stable during the process as shown in Figure 4.

The battery oscillator was fixed to a tensile testing machine and different displacements were applied to see the applied force effects. The horse bone was screwed on lower cross head of the machine. The reason for choosing horse bone is that it has an appreciable size for fixing. The horse bone was chemically treated to remove any grease. The horse bone is more or less dry and stiff.

The battery oscillator was run at full and half speeds to investigate the speed influence on cutting temperature.
The low thermal conductivity and porous structure of bone tissues make difficult for researchers to measure the temperature accurately in the cutting zone. Temperature measurement near the bone region in contact with the cutting tools is widely reported in literature [9]. The methods so far applied were bone imbedded thermocouples, toolimbedded thermocouples and infrared thermograph. Thermocouples are the most popular temperature measuring method due to its relatively low cost and wide range of temperature sensing abilities. Benington [10] recorded thermal images using Thermovision 900 system for drilling bovine bone. Due to the complexity of temperature measurements, Fluke Ti20 thermal camera was used to measure the temperature during bone cutting instead of thermocouples. The cutting temperature was measured with intervals of 5 seconds until the maximum level was reached. During bone cutting, the ceramic saw blade did not show a 
Citation: ljaz UM, David S, Ruediger H (2016) Ceramic Materials: An Alternative for Surgical Saws. Bioceram Dev Appl 6: 097. doi: 10.4172/20905025.1000097

Page 4 of 7

\begin{tabular}{|c|c|c|c|c|c|c|c|}
\hline \multirow[t]{2}{*}{ Material } & \multirow{2}{*}{$\begin{array}{l}\text { Moving distance } \\
(\mathrm{mm} / \mathrm{min})\end{array}$} & \multirow[t]{2}{*}{ Force (N) } & \multirow[t]{2}{*}{ Oscillator speed (/min) } & \multicolumn{4}{|c|}{$\begin{array}{c}\text { Cut Temperature } \\
\left({ }^{\circ} \mathrm{C}\right)\end{array}$} \\
\hline & & & & $5 \mathrm{sec}$ & $10 \mathrm{sec}$ & $20 \mathrm{sec}$ & Max. \\
\hline Stainless Steel & \multirow{2}{*}{1} & \multirow{2}{*}{$10-12$} & \multirow{2}{*}{6000} & 42.5 & 51.9 & 72.9 & 120.9 \\
\hline 3Y-Zirconia & & & & 40.1 & 45.8 & 59.0 & 94.5 \\
\hline $12 \mathrm{Ce}-\mathrm{ZrO}_{2}$ & 1 & $8-10$ & 6000 & 41.0 & 60.6 & 66.4 & 100.6 \\
\hline Stainless Steel & \multirow{2}{*}{2} & \multirow{2}{*}{$8-10$} & \multirow{2}{*}{12000} & 36.7 & 44.8 & 72.5 & 124.4 \\
\hline 3Y-Zirconia & & & & 36.0 & 43.4 & 47.8 & 82.4 \\
\hline $12 \mathrm{Ce}-\mathrm{ZrO}_{2}$ & 2 & $8-10$ & 6000 & 51.6 & 59.9 & 74.7 & 98.3 \\
\hline Stainless Steel & 3 & $12-14$ & 6000 & 70.4 & 80.0 & 93.1 & 111.1 \\
\hline 3Y-Zirconia & 3 & $6-8$ & 6000 & 48.7 & 56.9 & 82.2 & 99.0 \\
\hline $12 \mathrm{Ce}-\mathrm{ZrO}_{2}$ & 3 & $10-12$ & 6000 & 65.1 & 74.1 & 82.3 & 107.9 \\
\hline
\end{tabular}

Table 2: Temperature measurement of ceramics and stainless steel saw blades during bone cut.
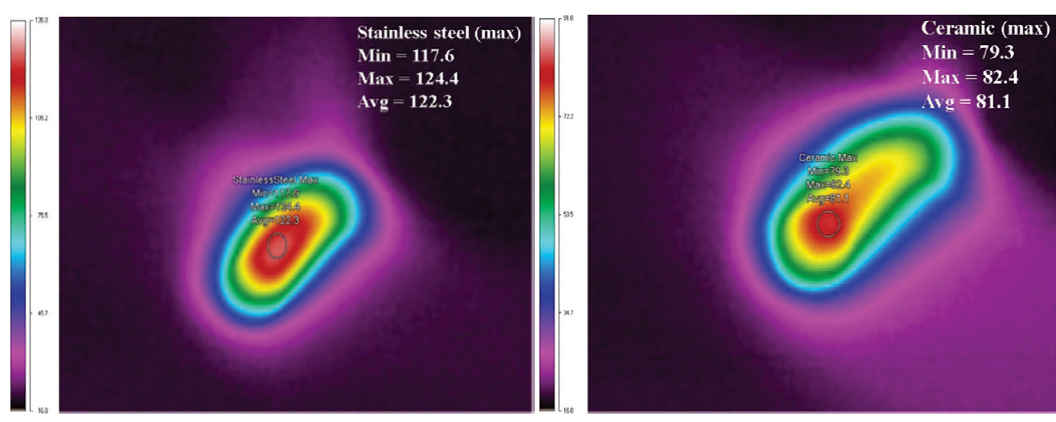

Figure 6: Fluke Ti20 thermal camera at bone cut by stainless steel saw and $3 \mathrm{Y}^{-} \mathrm{ZrO}_{2}$ ceramic (max. temperature)
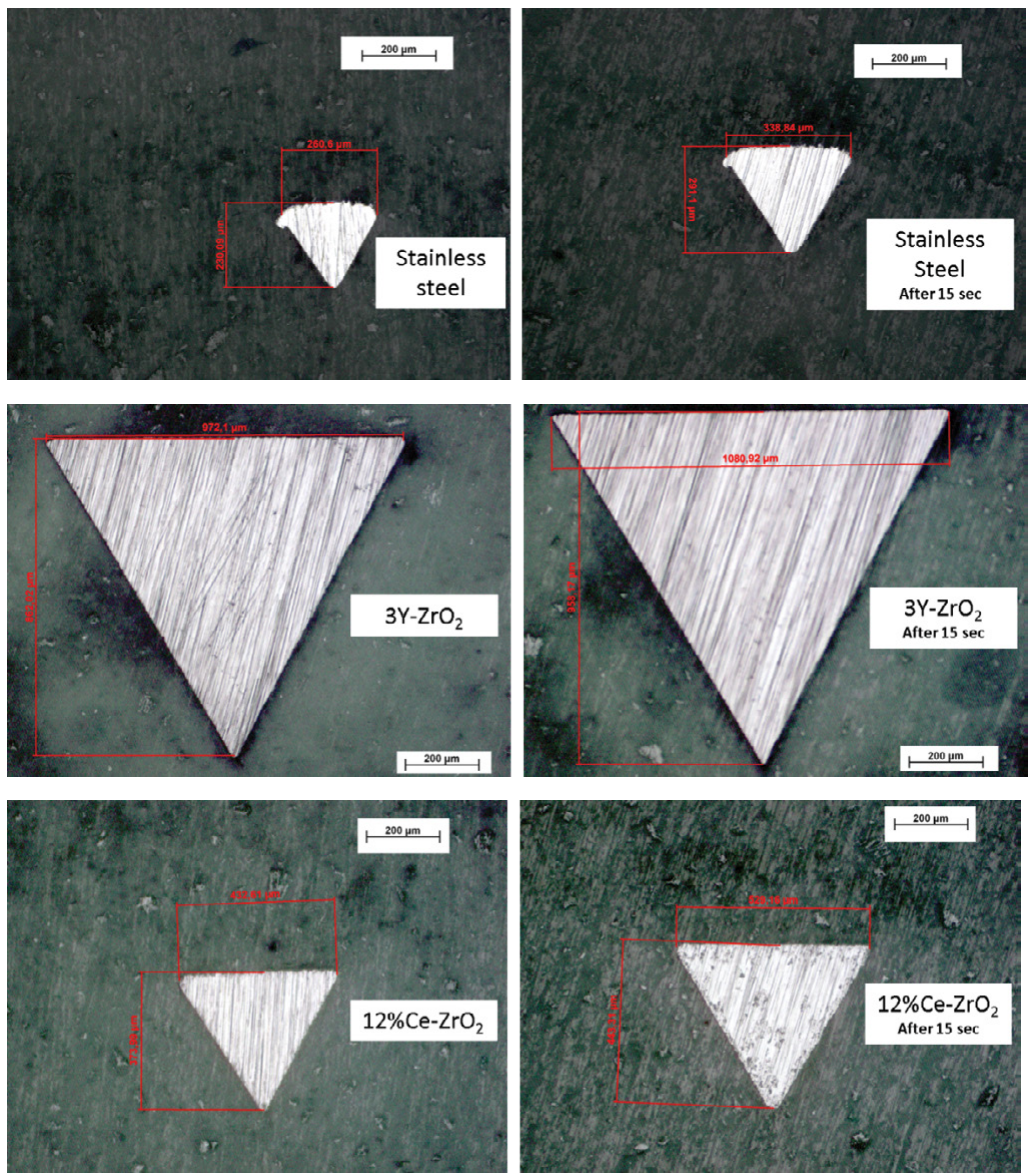

Figure 7: Abrasive resistance on SiC (p1000) 
big difference in temperature rise during the first 5 seconds interval (Figure 5). This can be explaining by the fact that the contact area of the ceramic saw blade was very small and friction coefficient became negligible. But when the contact area grew, a significant temperature difference was observed. The cutting temperatures for stainless steel and ceramic saw materials with different intervals are listed in Table 2. The applied force was approximately $8-12 \mathrm{~N}$ based on a movement distance of $1-2 \mathrm{~mm} / \mathrm{min}$ in the tensile machine.

Approximately 25\% reduction in temperature rise was observed in the dry bone cut with the ceramic saw as compared to the stainless steel saw blade as reported in Figure 6.

The abrasive resistance is a key factor for substituting stainless steel saw blade by ceramic saw blade. The abrasive resistance was checked by mounting the saw-teeth as metallography specimens. All samples were dry grinded with approximately force of $10 \mathrm{~N}$ on $\mathrm{SiC}$ paper ( $p$ 1000) for 15 second. Then grinded teeth were investigated by optical microscopy. The investigations revealed how much material was removed by grinding. The approximate area of the triangle was calculated as indicated in Figure 7.

Table 3 data indicated that $3 \mathrm{Y}$-zirconia has more abrasive resistance than stainless steel and ceria stabilized zirconia. Abrasive experiments were conducted to get a rough idea of wear resistance, since the wear resistance is an important factor for the life of ceramic blades.

$12 \mathrm{Ce}-\mathrm{ZrO} \mathrm{O}_{2}$ ceramic saw showed very bad sawing behavior and teeth loses their sharpness and also cracks were appeared on the teeth after two bone-cuts as dictated in Figure 8. This could be the result of less sintered density. The micro pores play role in generation of micro crack during bone cutting. By addition of $12 \%$ cerium content, fracture toughness supposed to enhance but on other hand decreases the sintered density. This revealed that $12 \mathrm{Ce}-\mathrm{ZrO}_{2}$ material is not suitable for these kind of the application. Bases on initial analysis, ceria stabilized material was skipped for further analysis.

Microscopic analyses after several bone cuts for both ceramic and stainless steel saws showed the advantages of ceramic saw-blade over stainless steel one, as shown below in Figure 9. The wear resistance of the ceramic material is better than of the stainless steel, but sharpness losses are little significant.

\section{HIP treatment of $3 \mathrm{Y}-\mathrm{ZrO}_{2}$ sintered blanks}

To address sharpness and micro-cracks issues in $3 \mathrm{Y}-\mathrm{ZrO}_{2}$ sintered saw blanks were hot isostatic pressed (HIP) which expected to improve quality.

\begin{tabular}{|c|c|c|}
\hline Material & Time of dry-grinding (sec) & Area of Saw-tooth increase after Grinding on SiC (p1000) paper (\%) \\
\hline Stainless steel & \multirow{2}{*}{15} & 64.50 \\
\hline 3Y-Zirconia & & 23.50 \\
\hline 12Ce-Zirconia & & 45.05 \\
\hline
\end{tabular}

Table 3: Data indicates that 3 Y-zirconia has more abrasive resistance than stainless steel and ceria stabilized zirconia.

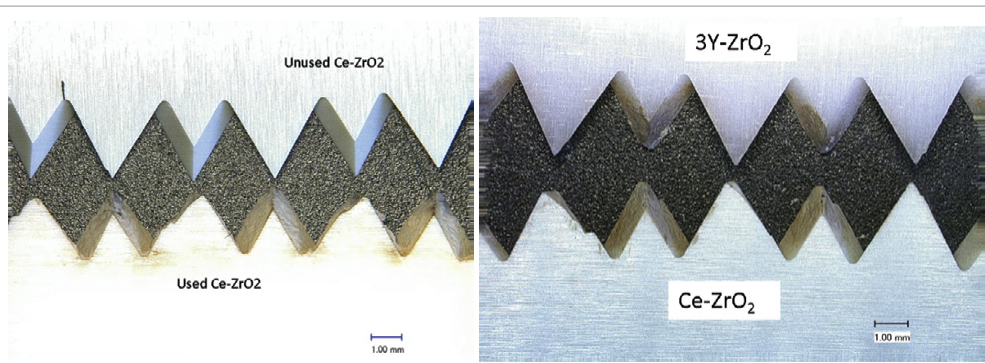

(a)

(b)

Figure 8: Ceramic saw blades teeth quality after single bone-cut: (a) comparison of used and unused $12 \mathrm{Ce}_{2} \mathrm{ZrO}_{2}$ Saws teeth, (b) comparison of $3 \mathrm{Y}^{-} \mathrm{ZrO}{ }_{2}$ and $12 \mathrm{Ce}-\mathrm{ZrO}{ }_{2}$
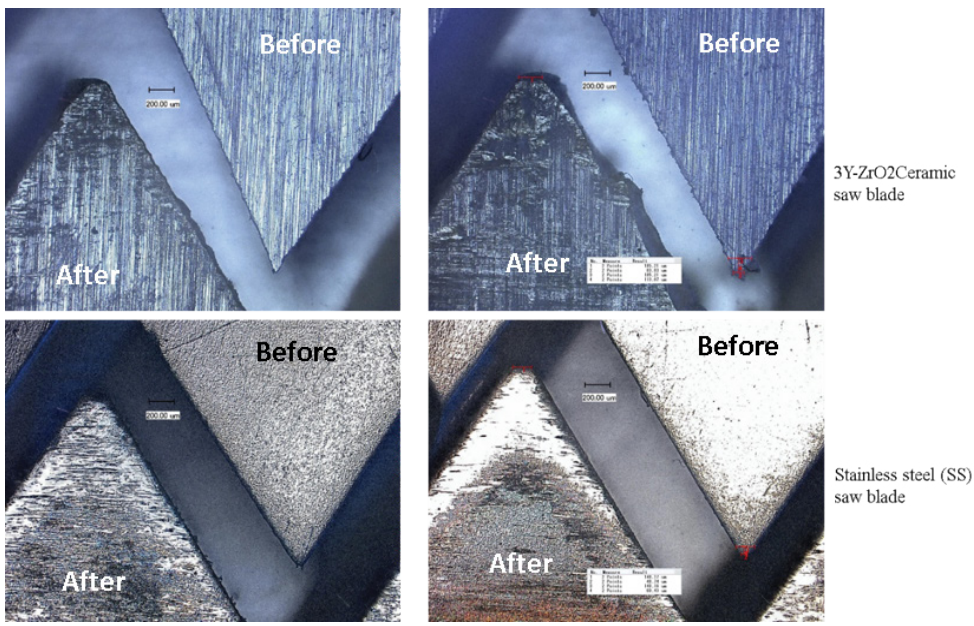

Figure 9: Wear of $3 \mathrm{Y}-\mathrm{ZrO}_{2}$ ceramic and stainless steel saw blades after several bone cuts. 

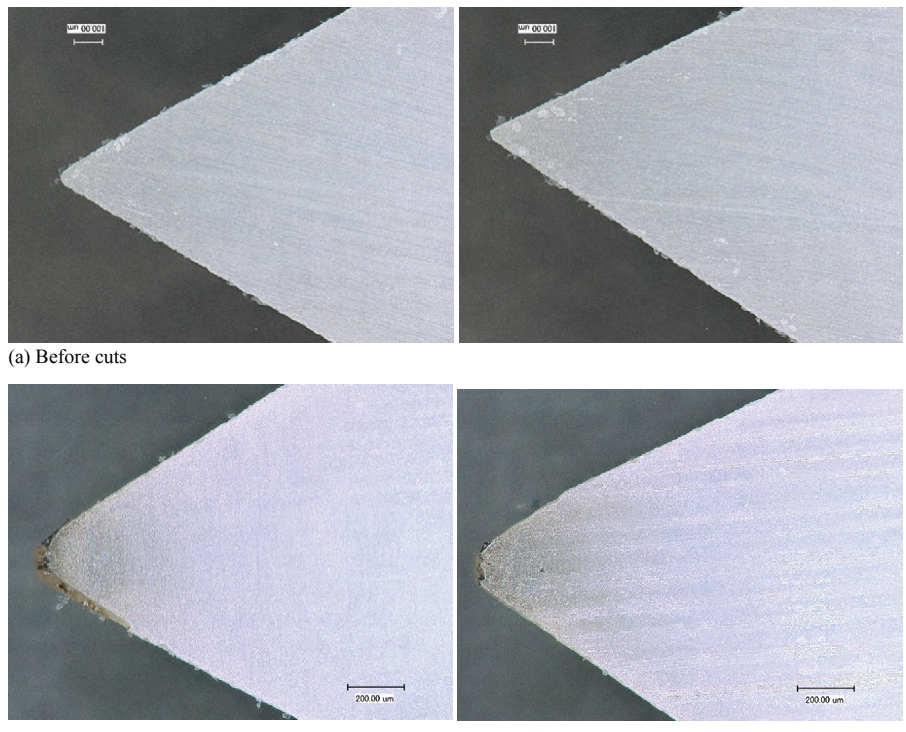

(b) After cuts

Figure 10: HIPed $3 Y-\mathrm{ZrO}_{2}$ Saw-blade teeth (after 4 bone cut) before (a) and after cuts (b).

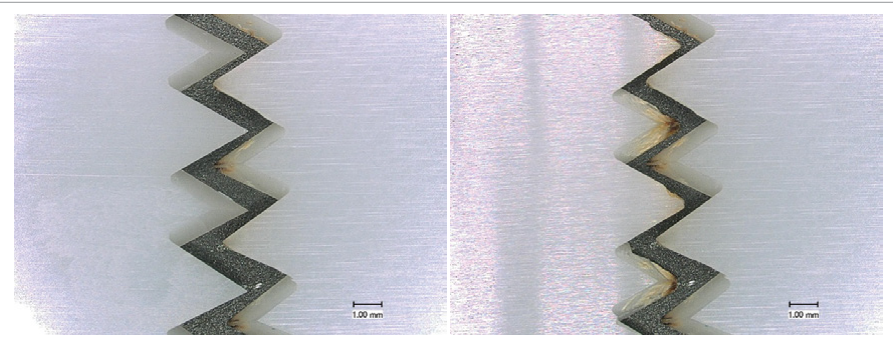

(a): HIPed 3Y-ZrO2 SAW blade un-used (left) and used (right)

(b): 3Y-ZrO2 SAW blades without HIPed (left) and HIPed (right) after bone cut

Figure 11: Comparison analysis of HIPed 3Y-ZrO2 SAW blades (a and b).

\begin{tabular}{|c|c|c|c|c|c|c|c|}
\hline \multirow{2}{*}{ Material } & \multirow{2}{*}{$\begin{array}{l}\text { Moving distance } \\
(\mathrm{mm} / \mathrm{min})\end{array}$} & \multirow{2}{*}{ Force (N) } & \multirow{2}{*}{ Oscillator speed (/min) } & \multicolumn{4}{|c|}{ Cut Temperature $\left({ }^{\circ} \mathrm{C}\right)$} \\
\hline & & & & $5 \mathrm{sec}$ & $10 \mathrm{sec}$ & $20 \mathrm{sec}$ & Max. \\
\hline \multicolumn{8}{|c|}{ Hipped $3 \mathrm{Y}-\mathrm{ZrO}_{2}$ Saw } \\
\hline $1^{\text {st }}$ Cut & \multirow{4}{*}{2} & \multirow{4}{*}{$8-10$} & \multirow{4}{*}{6000} & 34.4 & 45.3 & 61.8 & 91.3 \\
\hline $2^{\text {nd }}$ Cut & & & & 32.0 & 47.2 & 65.7 & 92.4 \\
\hline $3^{\text {rd }}$ Cut & & & & 30.6 & 45.0 & 63.3 & 91.2 \\
\hline $4^{\text {th }}$ Cut & & & & 33.1 & 44.2 & 68.2 & 95.8 \\
\hline
\end{tabular}

Table 4: HIPed ceramic $3 \mathrm{Y}-\mathrm{ZrO}_{2}$ saw blade temperature measured during bone cut.

The sintered $3 \mathrm{Y}^{-} \mathrm{ZrO}_{2}$ blanks were HIPed with heat rate of $10 \mathrm{~K} /$ min to $1400^{\circ} \mathrm{C}$ and pressurized at the same time upto 1500 bar with dwell time of 90 minutes.

After HIPing, saw-teeth was grinded. HIPed $3 \mathrm{Y}-\mathrm{ZrO}$, saw blades were employed for bone-cut testing. It was noticed that HIP process improved the strength of the material and sharpness loses issue somehow improved as shown in Figures 10 and 11. The HIPing process does not show big influence on cutting temperature during bone cut as listed in Table 4.

The significant lowering of temperature rises during bone cut makes evident the advantage of the ceramic saw blade over the stainless steel saw blade for orthopedic surgeries.

\section{Conclusion}

Ceramic saw blades were manufactured from $3 \mathrm{Y}-\mathrm{ZrO}_{2}$ and $12 \mathrm{Ce}-$
$\mathrm{ZrO}_{2}$ powder. The cutting temperature during the dry bone cut was measured with a thermal camera. Lowering in temperature rise during bone cut was attributed to the friction coefficient of the ceramic material, which is approximately 3 time less than of the stainless steel. The cutting temperatures were also compared between the stainless steel saw blade and the ceramic saw blade. Ceria stabilized zirconia showed bad sawing behavior and not suitable for this kind of application. The Hipping process significantly improved the teeth sharpness quality of the $3 \mathrm{Y}-\mathrm{ZrO}_{2}$. The lower elevated temperature and good mechanical properties supports the $3 \mathrm{Y}-\mathrm{ZrO}_{2}$ ceramic saw for substitution in orthopedic surgeries. Nevertheless, brittleness of the material can cause fracture at the saw teeth because machining of sintered ceramic is very critical to obtain well-defined sharp teeth edges.

\section{Acknowledgment}

Authors are thankful for their industrial partners Moeschter Group Holding 
Citation: ljaz UM, David S, Ruediger H (2016) Ceramic Materials: An Alternative for Surgical Saws. Bioceram Dev Appl 6: 097. doi: 10.4172/20905025.1000097

Page 7 of 7

GmbH \& Co. KG, Dortmund, Germany and Hipp Medical AG, Kolbingen, Germany for working cooperation. This project is funded by AiF $\mathrm{GmbH}$ with project number KF2018932AK4 and authors also appreciated AiF GmbH for providing funds for this research work.

\section{References}

1. Garvie RC, Hannink RHJ, Pascoe RT (1975) Ceramic steel? Nature 258: 703704.

2. Garvie RC (1983) Structural applications of $\mathrm{ZrO}_{2}$-bearing materials. In Adv Cera 12: 465-479.

3. Matsumato RK (1988) Aging behavior of ceria-stabilized tetragonal zirconia polycrystals. J Am Ceram Soc 71: 128-129.

4. McMeeking R, Evans AG (1982) Mechanics of transformation-toughening in brittle materials. J Am Ceram Soc 65: 242-246.
5. http://www.ceramono.de/reibungskoeffizient.html

6. Karmani $S$ (2006) The thermal properties of bone and the effects of surgical intervention. Current Orthopaedics 20: 52-58.

7. Christie J (1981) Surgical heat injury of bone. Injury 13: 188-190.

8. Moritz AR, Henriques FC (1947) Studies of thermal injury II. The relative importance of lime and surface temperature in the causation of cutaneous burns. Ame J Path 23: 695-720.

9. Khurshid A (2009) Experimental and numerical analysis of conventional and ultrasonically assisted cutting of bone. Loughborough University, Loughborough, UK.

10. Benington IC, Biagioni PA, Crossey PJ, Hussey DL, Sheridan S, et al (1996) Temperature changes in bovine mandibular bone during implant site preparation: an assessment using infra-red thermography. J Denti 24: 263-267. 